\title{
Not Principlism nor Casuistry, Not Narrative Ethics nor Clinical Pragmatism: A Case for Proceduralism
}

\author{
Courtenay R. Bruce
}

\begin{abstract}
Neither the method employed by philosophy nor theology nor anthropology nor history nor law nor any other methods that contribute to scholarship in medical ethics describe the blackbird called medical ethics in its entirety. But by examining a moral question from the vantage point of several different methods, one gains a richer understanding of that moral question, and a better grasp of an answer.
\end{abstract}

—Sugarman and Sulmasy, Methods in Medical Ethics, p. 4

\section{Introduction}

Finder allows the story arc of his case to intricately and poetically unfold, moving across various interpersonal domains and temporal sequences. Contrary to most case descriptions wherein the narrator and reader are detached, in "The Zadeh Scenario" Finder situates the case fully within the interpersonal context in which clinical ethicists operate, providing important contextual elements related to: dialogue, environment, emotionality, nonverbal and verbal cues, and stakeholders' perspectives. Without this degree of detail, the peer reviewers of Part Two would not have been able to analyze what occurred during the case and what could (or should) have been done differently. The reviewers were afforded an opportunity to critically appraise and reflect on the clinical ethicist's actions because of Finder's level of detail.

One of the most striking features of the reviewers' commentaries is that their assessments are largely devoid of ethical nomenclature like consequences, rights, and virtues. Their focus is practical and process-oriented rather than theory-driven. They, like Finder, often do not discuss the "ethics" of the case in any traditional

\footnotetext{
C. R. Bruce $(\bowtie)$

Institute of Academic Medicine, Houston Methodist Hospital, Houston, TX, USA

Texas A\&M University College of Medicine, Houston, TX, USA

e-mail: crbruce@ houstonmethodist.org
} 
sense, but spend considerable effort expounding on the lives, sufferings, stories, and doubts (personal and professional) that permeate the case. This focus does not imply that the reviewers lack a method; rather, their analyses suggest that their methods are interpersonal in nature, ones involving an interpretative process or a deliberate uncovering of ethical meanings (Agich 2005). A common feature that undergirds all of their assessments seems to be an implicit belief that engaging in patient care entails finding a clinically-feasible (but process-driven) solution.

In what follows, I will first outline what many considered the four most prominent (at least in the clinical ethics literature) methods for "doing" clinical ethics. For each I will also consider if, and how, the method may have been utilized in the peer reviews of Part Two. Where reviewers employ different methods within their analyses, or where they are unclear in their methods, I will draw attention to it. I will then shift attention to the method that I perceive as a common thread in all of the peer reviewers' assessments ("proceduralism"). This common thread can be seen as a combination of two existing methods, or even as an entirely new method. This new method, as I will explain, seems to be utilized in order to seek deeper understanding of the relationships between the experiences of individuals and their social frameworks, much like the narrative method. However, this method goes beyond the traditional story-focus of a narrative method by identifying and anchoring the problem within an ethical framework in which the clinical ethicist has an explicit goal of formulating and achieving an acceptable solution by using discrete process-steps. This method thus seeks to overcome some of the indeterminacy and tentativeness of stories by incorporating a procedural, objective layer within the ethical framework.

\section{Traditional Clinical Ethics Methods}

"Method" here refers to a systematic procedure, technique, or mode of inquiry employed during the clinical ethics consultation (Sugarman and Sulmasy 2001: 5). There is considerable debate within the clinical ethics community about the method for conducting ethics consultation, with four main contenders likely being principlism, casuistry, narrative ethics, and clinical pragmatism (Kuczewski 1998). Each of the methods vary in their theoretical grounding, in their process, and in their practical implications (Hurst et al. 2006).

\section{Principlism}

Originating in the late 1970s and early 1980s, the principlist approach to ethical decision-making has dominated Western bioethics for many years. The approach manifested through several publications around that time, including the Belmont 
Report, which identified basic principles that should guide research involving human subjects. Several books defended a principlist framework, most notably the work of Beauchamp and Childress (1979).

\section{Central Tenets}

(1) Ethical principles (e.g., autonomy, nonmaleficence, beneficence, and justice) and their guiding rules are central to ethical decision-making; (2) A decision is morally justifiable if that decision is consistent with the principles and their theoretical underpinnings; (3) The justificatory force of a decision can be measured by the degree to which it achieves an overall cohesion of all of the elements of the decisionmaking process (McCarthy 2003).

\section{Explanation}

The principlist approach holds that ethical theories (such as utilitarianism and deontology) are too general to guide specific actions, especially as they relate to clinical ethics consultation. Theories, however, give rise to more specific principles, and these principles are prima facie duties or obligations that the moral agent should perform. When duties conflict, like in a case where a patient with decision-making capacity requests treatment that is not considered medically beneficial (a conflict between autonomy and beneficence, at least at face value), we may not be able to fulfill all of our obligations. A conflict between duties requires us to balance the conflicting principles and determine which one has more weight. No single principle, duty, or rule has a priori priority (Kuczewski 1998). This weighing and balancing is referred to as "reflective equilibrium" (Beauchamp and Childress 1979). When choosing a solution, the infringement upon any one principle or duty must be minimized as much as possible, and we should seek to minimize the negative effects of the infringement.

\section{Strengths and Limitations}

This method for ethical decision-making uses an objective approach, allowing for replicability and transparent processes. The approach is versatile. Specifically, by describing the obligations as "prima facie," the principles can be considered morally equivalent at face value but can be given priority in certain situations (McCarthy 2003). Criticisms about this method generally center on its application. Some have argued that the method is too theoretical and cannot be easily applied to clinical realities in any sort of practical way: "ethical principles offer limited guidance for the clinical tasks of caring for patients" (Block and Billings 1994). 


\section{Commentaries' Appeals to Principlism}

Principlism is rarely discussed in most of the reviewers' assessments, which could suggest that this ethical framework is outdated, has limited applicability in their analyses, or that they found other methods more useful when analyzing the case. Most likely, their lack of discussion about principlism reflects a combination of these and other factors. Where principlism is invoked, it is implicit in discussion about ethically appropriate treatments. For instance, Tarzian writes: "The difficulty in identifying which 'grey zone' interventions qualify as 'medically inadvisable' rests on judgments about which goals for Mrs. Hamadani are of "controversial value"' (Tarzian 2018: 81). Tarzian appeals to beneficence-based judgments by calling for a clinical evaluation of the interventions that would be empirically, quantifiably medically beneficial to achieve physiologic and ethical goals. Further, Hynds writes, "most problematically [in Finder's report]...is that there is little actual 'ethics' consultation occurring in this case...no attempt...to identify, analyze, or resolve values uncertainty or conflict qua its being value uncertainty or conflict....The family needs to know...that it is explicitly for ethical reasons (i.e. reason of professional value or core commitment) that [Dr. Broukhim] does not want to offer more treatment" (Hynds 2018: 95-6). In essence, Hynds is looking for consultative method, some framework by which to analyze the case and reach a judgment, and he appeals to the virtue of professional integrity in doing so. Likewise, all of the commentaries mention the importance of hearing the patient's voice for autonomy-enhancing purposes, which is consistent with principlism.

\section{Casuistry}

Casuistry became popular in the 1990s as an alternative to theory-driven application of principles by viewing clinical ethics as dealing with concrete problems and unique cases (Agich 2005). Unlike principlism, casuists do not apply principles to cases in an inferential manner. Jonsen (who may be said to be the individual most responsible for re-introducing casuistry to the bioethics community) defines casuistry as:

\footnotetext{
The interpretation of moral issues, using procedures of reasoning based on paradigms and analogies, leading to the formulation of expert opinion about the existence and stringency of particular moral obligations, framed in terms of rules or maxims that are general but not universal or invariable, since they hold good with certainty only in the typical conditions of the agent and circumstance of action. (Jonsen 1991a, b: 297)
}

\section{Central Tenets}

Jonsen identifies three stages of moral reasoning in using casuistry: (1) Identify the case and its relevant features, including the moral problems; (2) Compare the case to other cases, especially paradigmatic cases; (3) Use analogies to determine the fit between the case at hand and the paradigm cases (Kuczewski 1998; Jonsen 1995). 


\section{Explanation}

Casuistry differs from principlism in that no single principle, rule of thumb, or maxim can be affirmed. Casuistry holds that principles are too vague. The ethicist discovers and elucidates principles by exploring cases. That is, principles cannot guide action until content is provided through paradigmatic cases (Kuczewski 1998). The clinical ethicist should consider cases where the principle applies and contrast them with cases where the principle could be suspended.

\section{Strengths and Limitations}

Casuistry is persuasive in its practicality, especially given its emphasis on actual clinical ethics cases. It also has the benefit of working with principlism, and most advocates of casuistry do not view the methods as mutually exclusive or incongruent. That is, many advocates of casuistry view case methods as more basic and more reliable than maxims or principles, with rules coming into play in order to give direction once the case is evaluated and compared. On this point, Jonsen uses an example where he analogizes a bicycle to a practical judgment and a hot-air balloon to ethical theory: "The balloon of theory can give us orientation of mind and exhilaration of moral imagination. However, we are not tethered to the balloon; we do not need it for moment-to-moment directions through ethical problems. The balloon is an occasional extravagance. The bicycle is daily transportation and exercise" (Jonsen 1991a, b: 16). The criticisms surrounding casuistry include questions of bias and the constitution of paradigmatic cases. Bias can arise in casuistry when: describing the selection criteria for a certain case, stating the problem to be examined and exemplified, choosing a comparison case, and identifying the selected paradigmatic case (Kopelman 1994).

\section{Commentaries' Appeals to Casuistry}

While there is no systematic appeal to casuistry within the commentaries, there are several times when commenters seem to make some sort of casuistic-like appeals. What remains unclear, however, is why a particular perspective is presented as paradigmatic, and why the specific features are identified as ethically relevant. To the extent that casuistry is employed, it is generally invoked in a very legalistic sense. For example, Rosell and Johnson write: "Just as patients have the ethical and legal right to refuse treatment, physicians and healthcare providers are ethically, and sometimes legally, allowed to refuse to treat patients... Some laws for individual states within the United States (e.g. Texas) require physicians to transfer the patient's treatment to another provider...In this case..." (Rosell and Johnson 2018: 101). They thus seem to be using legal statutes as paradigms with which to examine the scenario Finder presents, but it is unclear how these statutes would be applied in this 
situation - let alone whether these laws actually are applicable in this case. What is needed to answer that question is more detail relating to how or why such laws should be applied.

\section{Narrative Ethics}

Narrative ethics deploys narratives and methods derived from world literature as a basis for assessment. Narrative ethics calls for masterful skills in observation, interpretation, and elucidation of patients' values and experiences (Hunter et al. 1995).

\section{Central Tenets}

The study of narrative ethics is young, making it difficult to discern a clear articulation of its central tenets. McCarthy provides perhaps the clearest and most concise version: “(1) Every moral situation is unique and unrepeatable and its meaning cannot be fully captured by appealing to law-like universal principles; (2) Any decision...is justified in terms of its fit with the individual life story or stories of the patient; (3) The objective of the task of justification in 2 is not necessarily to unify moral beliefs and commitment, but to open up dialogue...[and] explore tensions" (McCarthy 2003: 67).

\section{Explanation}

An essential premise behind the narrative approach is a belief that the patient's story (or narrative) is a rich source of qualitative data that could be used to inform the clinical ethicist's assessment and analysis. In most ethics consultations, elucidating a patient's moral life story is a key procedural task for the clinical ethicist. Indeed, the moral values and life circumstances of patients will often need to be elucidated and carefully documented as part of the information-gathering efforts that occur early on during the ethics consultation. As Dubler and colleagues describe:

The medical team is the expert on illness and disease, but the family is the expert on

'Mama.' Plumbing their perceptions and encouraging them to tell their stories helps to bring the patient to the center of the discussion and gives voice to and empowers the family amidst the alien discourse of medicine. (Dubler et al. 2009: 26)

To elucidate the patient's story, the ethicist uses open-ended elucidation questions. The most credible stories are those that adequately and fully capture significant events in a person's life (McCarthy 2003; Brody and Clark 2014). Narrativists do not focus on trying to reduce competing perspectives or to reconcile them; rather, they focus more on bringing as many people into the dia- 
logue as possible to optimize chances of respecting all the persons involved in the case. Empathetic listening and support are considered paramount in this process (McCarthy 2003).

\section{Strengths and Limitations}

Narrative ethics poses a nice contrast with principlism. The narrative approach seeks to incorporate multiple perspectives, which is important for inclusion purposes and for conducting a robust analysis. Narrative ethics also introduces the idea that ethics should not be only concerned with reducing discord. But this "strength" also serves as a point of criticism. Specifically, there is an element of indeterminacy in stories and those who are interested in narrative ethics are most interested in enduring moral character and less interested in what a person should do (Brody and Clark 2014). The challenge in clinical ethics, however, is that indeterminacy is typically unsatisfactory for the consult requestor. He or she needs to know what to do, otherwise a consult request would never have been placed. Indeterminacy drove the consult request, and the case should not be "resolved" by simply introducing more uncertainty.

\section{Commentaries' Appeals to Narrative}

Finder's account in "The Zadeh Scenario" and the peer reviewers' responses are replete with narrative examples, with each one of them embracing some form of narrative. Indeed, Finder's conclusion echoes narrativist sentiments: "We often proceed as if endings need to be smooth and unitary, all the loose strings tied up together into an easily digestible resolution. But why should that be when the very context, and content, of such meetings concern a kind of coming apart, a dissolution, an undoing of a moment that has lasted possibly 83 years?" (Finder 2018: 42). We also see that references to "the narrative" or "story" appear at least ten different times among all of the commenters' assessments, with each commentary mentioning it at least once. For instance, Armstrong writes: "Finder's polished skills of careful attention and mindful appreciation in recounting the 'doing' of an ethics consult thus provide something of an anthropological account-telling us who went where and the content of several weighty conversations" (Armstrong 2018: 63). And Frolic $\&$ Rubin write that "[Finder] offers us a case narrative into which he has chosen to place himself squarely and explicitly...individuals inevitably become 'characters' based on how other people perceive them and the social roles they play" (Frolic and Rubin 2018: 47).

On the one hand, the reviewers' applaud Finder for the richness in which he tells the story. They also credit him for using open and well-crafted questions that allows him to elucidate the family's story. This prompting, in turn, allows him to more fully understand the family's moral perspectives. On the other hand, however, they are quick to identify one story that is notably lacking in the case presentation: that of the 
patient. Rosell \& Johnson write, "there also is evidence in 'The Zadeh Scenario' of notable inattention...In this narrative, where is the patient?" (Rosell and Johnson 2018: 106). Armstrong writes: "It is concerning that "The Zadeh Scenario" narrative fails to explicitly identify and analyze whose wishes are being expressed, instead focusing on the role of the patient's children in decision-making" (Armstrong 2018: 68).

\section{Clinical Pragmatism}

A fourth model of ethics consultation adopts a process model of moral problemsolving and deliberation. Here, the facts of the case unfold and are assessed in a dynamic process of inquiry in order to achieve a resolution that is within the range of an ethically appropriate plan of care. It is considered dynamic in the sense that it concerns interactions between clinicians, patients or their surrogates, and the clinical ethicist.

\section{Central Tenets}

This model uses a systematic approach involving the following steps: (1) Assess the patient's situation (capacity, values, beliefs, preferences, and prognosis) and determine the point of ethical concern; (2) Determine the appropriate goals of medical care, including what types of treatment are appropriate or inappropriate and on what basis. (3) Arrive at a clinically and ethically appropriate plan (Jonsen et al. 2006; Miller et al. 1996; Dewey 1944).

\section{Explanation}

Borrowed heavily from Dewey's work, clinical pragmatics treats ethical theories (consequentialism, deontology, and virtues) as tools to guide problem-solving. The emphasis is on reconstructing ethical thinking to integrate it with clinical judgment. By focusing on concrete problems and practical considerations to facilitate resolution of the case, it retains clinical significance. In other words, this approach adopts a process model to solve moral problems, instead of a "judgment" model that is typical of casuistry and principlism (Miller et al. 1996).

\section{Strengths and Limitations}

The most salient positive feature of this model is that it attends to the interpersonal nature of ethics consultation, while also recognizing that there are substantive decisions to make. In this way, it goes beyond narrative ethics by focusing on actually 
resolving the case at hand. Further, by merging ethical and clinical thinking, it is achieves goals of ethicists and clinicians alike (Miller et al. 1996). A drawback of this model is that it does little to specify the actual steps that should be taken other than broad-level enumeration. It emphasizes the importance of interpersonal relations, but stops short of discussing how stories should be integrated within the decision-making calculus, or how conflict-resolution skills or ethical appeals should be applied.

\section{Commentaries' Appeals to Clinical Pragmatism}

The clearest examples of this approach can be gleaned from Tarzian's commentary. The word "process" appears as the third word in her assessment, setting the stage for what is to come. She identifies several process measures she would have implemented in an ethics consultation that appear not to have been implemented by Finder. Like several of her peer reviewers' commentaries, she emphasizes the importance of identifying with what a requestor wants help and then clarifying how the ethics consultant could or could not assist. She, like others, believes this was not done in Finder's case or, at the very least, was not clearly articulated in "The Zadeh Scenario." She goes on to write,

From this point on, however, there is ambiguity in several procedural aspects of how this consultation was handled. First, it was not entirely clear how limits on Dr. Moore's involvement would be communicated to other staff... Second, it's not clear that Finder has clarified what role he will play in the case. (Tarzian 2018: 79)

In short, Tarzian seems implicitly to believe that, because certain process standards were neither acknowledged nor adhered to, it is unclear whether the case was fully resolved, how the ethics consultant contributed to the case, and whether the healthcare professionals involved in this case felt supported by Finder's involvement.

\section{Reflecting a New Method: Learning from the Peer Reviews}

While the clinical ethics literature is filled with appeals to, or arguments for or against, the above briefly discussed methods, in their responses to "The Zadeh Scenario," the reviewers consistently appeal to both procedural standards and narrative themes throughout. This combination of pragmatic and narrative appeals serves a crucial role: it makes up for the shortcomings of each of the methods. Whether intentional or not, the method suggested by these peer reviews is persuasive in its idiosyncrasies because it draws on the best features of each respective method and avoids the weaknesses.

Consider Tarzian's peer review. She is explicit about commitment to pragmatism when she writes, "Attending mindfully to the process of how health care ethics consultation is done is just as important as demonstrating that ethics consultants have requisite skills and knowledge" (Tarzian 2018: 75). And yet, at the same time, 
Tarzian seems to be quite cognizant of the fact that this approach is too linear, too non-descript. Its emphasis on practical considerations does little to explicate the process steps to be taken or avoided. Hence, Tarzian, goes beyond pragmatism by also appealing to professional standards (articulated by ASBH and PHEEP) as her structural basis. She then lists defined procedural elements, as enumerated by these professional organizations, with one step including narrative interpretation. Here are the procedural elements she describes:

1. Clarify the consult request. Why is the requestor requesting an ethics consultation? What is it he or she perceives as the point of ethical concern? What degree of involvement is he or expecting? (This point was reiterated by several reviewers, suggesting they consider it to be a critical preliminary process-step.)

2. Communicate how colleagues' roles might be limited. What might clinicians expect of colleagues? How will they be interacting with the ethics consultant? Who will "stay on" the case, and in what capacity?

3. Determine what role should be taken during a family meeting. Will the clinical ethicist lead the family meeting? Facilitate conversation? Observe the meeting? On what basis is this judgment to be made, and to whom should this be communicated?

4. If the point of concern is one involving medically inappropriate treatments, then clarify which treatments are considered inappropriate and on what basis this judgment is made. What is the desired goal of the intervention? Can it be achieved? Is there agreement among the clinicians about the appropriateness or inappropriateness of a treatment?

5. Particularly in cases where there are numerous healthcare professionals involved, and where there is a high degree of intellectual or emotional weariness, consider a team only meeting to (a) identify which treatments are inappropriate and on what basis; (b) streamline and facilitate communication; (c) delineate options; and (d) formulate a plan of care that is shared and agreed-upon.

6. Appeal to professional standards, literature, law, and professional guidance statements to guide clinical ethicists' consultative activities and provide justifications for actions taken. (This approach runs along similar lines as casuistry.)

7. It is important to unpack clinicians, patients, and surrogates' perspectives, thoughts, and beliefs (appealing to narrative ethics). The narrative approach comes up less in Tarzian's review than it does in the other commentaries, but there are elements of it throughout her commentary: (a) "While Dr. Finder recognizes these cultural differences in his write-up of "The Zadeh Scenario," it's unclear whether or how he addressed these conflicts in his role as the ethics consultant" (Tarzian 2018: 80); (b) "Perhaps like the Iranian physician...Dr. Broukhim struggles with what T'aarof demands in these situations" (Tarzian 2018: 82); (c) "He also would not be the first oncologist who needs support accepting his own patient's death and guidance in how to help families do the same" (Tarzian 2018: 83); 
8. There needs to be an attempt to resolve the case, move it along, and address the underlying ethical issues. As Tarzian states: "Being a good listener is necessary — but not sufficient—-for being an effective ethics consultant" (Tarzian 2018: 83). More than just listening to stories, ethics consultants must actually use those stories within a procedural framework to address value-laden uncertainty or ethical conflict. The narrative component, then, is just a layer, a step, within the procedural framework required for conducting an ethics consultation.

9. To address the issue, the ethics consultant may need to use a combination of active listening skills and conflict-resolution skills. The conflict resolution skills may take a form of mediation (perhaps entailing a compromise where it is ethically permissible) or a more directive communication approach (like defining boundaries on what constitutes appropriate/inappropriate medical treatment and what therapies will or will not be offered). This also could be conceptualized as extending beyond simple narrative ethics by boundary-drawing, where appropriate.

Indeed, each peer reviewer in Part Two invokes narrative and procedural components. Each uses at least some professional standards to serve as the basis for the inclusion of procedural elements. So what is this method? Is it simply a combination of narrative ethics and pragmatism? I suggest it is a far more particularized, systematic approach than either one of those methods call for. It is pragmatic, but is more than just practical. It is less about just, so to speak, "being in the trenches" by interacting with clinicians and patients/surrogates, which is precisely what the pragmatic approach calls for, and instead calls for being in the trenches in a very systematic, procedural-oriented way that is in keeping with agreed-upon professional standards (to the extent there are agreed-upon professional standards, articulated by ASBH). Additionally, it is less about just hearing the stories, which is precisely what the narrative method calls for, and instead relies on stories to formulate the basis for clinical ethicists' recommendations and action-oriented "plans" or "steps" for resolving the case. Narrative ethics is not used as a singular consultation methodology; rather, it is used as one procedural step among many that need to be taken to conduct the consult well.

In short, this method, which may more properly be referred to as "proceduralism," is distinct from both narrative ethics and clinical pragmatism. Proceduralism allows for internal consistency and justificatory force to the extent that certain steps should be followed and justifications provided if these steps are not followed. It is based on professional standards but allows for exceptions that are case-specific. One could theorize that a shift towards proceduralism occurs because of (or ancillary to) professionalization movements of clinical ethics. The creation and promulgation of a standard process for certifying clinical ethicists leads to a desire for a structural, procedural framework to guide clinical ethicists' methods. Furthermore, such an approach is conductive to checkboxes and criteria, performance improvement, and overall quality improvement efforts that serve as the hallmark of contemporary healthcare. 


\section{Conclusion}

The reviewers in Part Two employ bits and pieces of several different methods, drawing on those features they find helpful, while avoiding those features that prove to be less helpful in their analyses. They apply very little principlism (only implicitly, really) and casuistry. Where they use casuistry, it is often appealed to somewhat incompletely or irreverently. In contrast, their reviews contain several narrative and pragmatic elements, which I suggest might be indicative of a shift towards a new method, one that echoes narrative and pragmatism approaches while using procedural standards to orient their method.

More work is needed to confirm whether this is an entirely new method or whether it is simply a combination of narrative ethics and pragmatism. In the interim, I can make some preliminary recommendations for peer review of clinical ethics consultations, based on what I am able to extrapolate from my colleagues' reviews. First, it is important to be deliberate and explicit in the approach taken. If one of the procedural steps enumerated above is not taken, then the consultant should provide a justification for doing so. Second, identify the nature of the ethical concern early, including how one, as the clinical ethicist, could or should assist in this case. Third, be explicit in one's role by explaining what one will be doing in the case and why. Fourth, in order to move a case toward resolution, it is important to identify which interventions or actions are considered inappropriate and for what reasons. In the absence of these and other activities enumerated more fully above, it may be difficult fully to evaluate the work of clinical ethics colleagues, other than to say there is always value in listening to patients, surrogates, and clinicians.

\section{References}

Agich GJ (2005) What kind of doing is clinical ethics? Theor Med Bioeth 26(1):7-24

Armstrong K (2018) Telling about engagement is not enough: seeking the "ethics" of ethics consultation in clinical ethics case reports. In: Finder SG, Bliton MJ (eds) Peer review, peer education, and modeling in the practice of clinical ethics consultation: the Zadeh project. Springer, Cham, pp 63-73

Beauchamp JF, Childress TL (1979) Principles of biomedical ethics. Oxford University Press, New York

Block SD, Billings JA (1994) Patient requests to hasten death. Evaluation and management in terminal care. Arch Intern Med 154(18):2039-2047

Brody H, Clark M (2014) Narrative ethics: a narrative. Hast Cent Rep 44(1 Suppl): S7-S11

Dewey J (1944) Human nature and conduct. Published for the United States Armed Forces Institute by Henry Holt, New York

Dubler NN, Webber MP, Swiderski DM et al (2009) Charting the future. Credentialing, privileging, quality, and evaluation in clinical ethics consultation. Hastings Cent Rep 39(6):23-33

Finder SG (2018) The Zadeh scenario. In: Finder SG, Bliton MJ (eds) Peer review, peer education, and modeling in the practice of clinical ethics consultation: the Zadeh project. Springer, Cham, pp 21-42 
Frolic A, Rubin SB (2018) Critical self-reflection as moral practice: a collaborative meditation on peer review in ethics consultation. In: Finder SG, Bilton MJ (eds) Peer review, peer education, and modeling in the practice of clinical ethics consultation: the Zadeh project. Springer, Cham, pp 47-61

Hunter KM, Charon R, Coulehan JL (1995) The study of literature in medical education. Acad Med 70(9):787-794

Hurst SA, Chevrolet JC, Loew F (2006) Methods in clinical ethics: a time for eclectic pragmatism? Clin Ethics 1(3):159-164

Hynds J (2018) Ethics consultation, professional praxis, and what it means to be a "consultant". In: Finder SG, Bilton MJ (eds) Peer review, peer education, and modeling in the practice of clinical ethics consultation: the Zadeh project. Springer, Cham, pp 85-97

Jonsen AR (1991a) Casuistry as methodology in clinical ethics. Theor Med 12(4):295-307

Jonsen AR (1991b) Of balloons and bicycles - or - the relationship between ethical theory and practical judgment. Hastings Cent Rep 21(5):14-16

Jonsen AR (1995) Casuistry: an alternative or complement to principles? Kennedy Inst Ethics J 5(3):237-251

Jonsen AR, Siegler M, Winsdale WJ (2006) Clinical ethics: a practical approach to ethical decisions in clinical medicine, 6th edn. McGraw Hill, New York

Kopelman LM (1994) Case method and casuistry: the problem of bias. Theor Med 15(1):21-37

Kuczewski M (1998) Casuistry and Principlism: the convergence of method in biomedical ethics. Theor Med Bioeth 19(6):509-524

McCarthy J (2003) Principlism or narrative ethics: must we choose between them? Med Humanit 29(2):65-71

Miller FG, Fins JJ, Bacchetta MD (1996) Clinical pragmatism: John Dewey and Clinical ethics. J Contemp Health Law Policy 13(1):27-51

Rosell T, Johnson B (2018) This may, or may not, be an ethics consultation. In: Finder SG, Bilton MJ (eds) Peer review, peer education, and modeling in the practice of clinical ethics consultation: the Zadeh project. Springer, Cham, pp 99-107

Sugarman J, Sulmasy DP (2001) Methods in medical ethics, 1st edn. Georgetown University Press, Washington, DC

Tarzian AJ (2018) Ethics consultation for Mrs. Hamadani: a focus on process. In: Finder SG, Bilton MJ (eds) Peer review, peer education, and modeling in the practice of clinical ethics consultation: the Zadeh project. Springer, Cham, pp 75-84

Open Access This chapter is licensed under the terms of the Creative Commons Attribution 4.0 International License (http://creativecommons.org/licenses/by/4.0/), which permits use, sharing, adaptation, distribution and reproduction in any medium or format, as long as you give appropriate credit to the original author(s) and the source, provide a link to the Creative Commons license and indicate if changes were made.

The images or other third party material in this chapter are included in the chapter's Creative Commons license, unless indicated otherwise in a credit line to the material. If material is not included in the chapter's Creative Commons license and your intended use is not permitted by statutory regulation or exceeds the permitted use, you will need to obtain permission directly from the copyright holder.

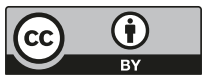

